\title{
Mechanical Properties Degradation at Room Temperature in ZRY-4 by Hydrogen Brittleness
}

\author{
G. Bertolino ${ }^{a}$, G. Meyer ${ }^{a / c}$, J. Perez Ipiña $^{b / c *}$ \\ ${ }^{a}$ Centro Atómico Bariloche, Instituto Balseiro, CNEA, \\ Bustillo 9500, (8400) S.C. de Bariloche \\ ${ }^{b}$ Universidad Nacional del Comahue, \\ Buenos Aires 1400, (8300) Neuquén \\ ${ }^{c}$ CONICET
}

Received: August 28, 2001; Revised: April 14, 2002

\begin{abstract}
A hot rolled Zircaloy-4 alloy, annealed with a final cold rolling, presenting rounded grains, was studied. Hydrogen cathodic charge with a homogenization heat treatment was used to pre-charge the specimens with different hydrogen contents. Hydrogen embrittlement susceptibility analysis was held using $\mathrm{J}$ integral and J-R curve results from CT specimens (compact tension specimens) tested at room temperature. As $\mathrm{J}_{\mathrm{IC}}$ values showed scatter, toughness was evaluated for $\Delta \mathrm{a}=1 \mathrm{~mm}$. Toughness clearly tended to decrease as hydrogen content increased abruptly for low $\mathrm{H}$ contents and gradually for high contents. A few specimens with high hydrogen content failed in brittle mode, or presented instability and posterior crack arrest. Fractographic observations showed that, despite the records had presented no signs of brittle fracture, certain specimens showed cleavagelike zones. More cleavage-like area percentage was present the higher the hydrogen content was.
\end{abstract}

Keywords: mechanical properties, delayed hydrogen cracking, zircaloy, hydrides

\section{Introduction}

It has long been known that Zirconium-based cladding alloys absorb hydrogen as a result of servicing in a reactor environment. Hydrogen can be absorbed from different potential sources: from hydrogen cathodically generated as a result of the corrosion of the cladding by the primary side water coolant, from hydrogen gas dissolved in the primary side coolants in pressurized water reactors, and from hydrogen released by corrosion of gases or vapors containing hydrogen in the internal plenum region of the rods. In the last years much attention has been devoted to the degradation of the mechanical properties of zirconium-based alloys both by hydrogen embrittlement and irradiation hardening.

At normal reactor operating temperatures hydrogen has limited solubility in the zirconium lattice and mostly precipitates out of the solid solution as Zirconium hydride ( $\mathrm{ZrH}) . \mathrm{ZrH}$ precipitation embrittles the zirconium alloy, thus reducing both ductility and fracture toughness. Hydrogen embrittlement is considered as one of the main failure mechanisms in the nuclear reactor structural elements be- cause hydrogen rich environment plus physical conditions favor hydrogen absorption ${ }^{1}$. Delayed hydride cracking (DHC) in zirconium-based alloys has been known as a potential failure mechanism in CANDU reactor pressure tubes ${ }^{2}$. Because of the stress field dominating the crack tip zone, it was observed that hydrogen diffuses into this area and precipitates as hydride, preferently with a direction perpendicular to the largest tension stress component. It was also observed that a crack can be generated at some typical defects and the subsequent growth mechanism is due to hydride formation ahead the crack tip -crack grows through either them or the matrix interface- generating new hydride precipitates and so on ${ }^{2}$.

The aim of this work was to study the variation of fracture toughness of a zirconium-based alloy, Zircaloy-4, at different hydrogen contents.

\section{Material and Method}

\section{Material}

The study was carried out using a Zircaloy-4 alloy (Zry-4) $6 \mathrm{~mm}$-thick slab, hot rolled and annealed with final cold 
rolling (Compagnie Europenne du Zirconium CEZUS). Its main alloying elements were $\mathrm{Fe}(0.22 \% \mathrm{wt}), \mathrm{Cr}(0.1 \% \mathrm{wt})$, Sn $(1.4 \% \mathrm{wt})$ and $\mathrm{O}(0.128 \% \mathrm{wt})$, while its microstructure consisted of $10 \mu \mathrm{m}$ diameter rounded grains, Fig. 1. The original hydrogen content was about $10 \mathrm{ppm}$.

The mechanical properties reported by the manufacturer are shown in table 1.

\section{Specimens preparation}

Compact tension (CT) specimens were machined to $\mathrm{W}=25.4 \mathrm{~mm}$ and $\mathrm{B}=6 \mathrm{~mm}$ (slab thickness) with the rolling direction normal to the crack plane (LT). The dimensions were in accordance with the standard ASTM E 1820$99^{3}$.

Specimens were fatigue pre-cracked up to a/W ratios (crack length to specimen width ratios) between 0.45 and 0.55 , in accordance to standard procedures.

Specimens surfaces were mechanically polished and then etched with a $25 \%$ lactic acid, $25 \%$ water, $46 \% \mathrm{HNO}$ and $4 \% \mathrm{HF}$ solution before the hydrogen charge. The cathodic charge was performed in a $0.1 \mathrm{M} \mathrm{KOH}$ solution with a $0.5 \mathrm{~A}$ current. Finally specimens were heat-treated during 6 hours in argon or hydrogen atmosphere at $450{ }^{\circ} \mathrm{C}$; and then cooled inside the furnace, slowly down to room temperature.

\section{Testing method}

The tests were carried out using a servohydraulic ma-

Table 1. Mechanical Properties at room temperature.

\begin{tabular}{lcc}
\hline Property & Longitudinal & Transversal \\
\hline$\sigma_{\text {UTS }}[\mathrm{MPa}]$ & 522 & 510 \\
$\sigma_{\mathrm{y}}[\mathrm{MPa}]$ & 365 & 460 \\
Elongation $\%$ & 27.8 & 28.6 \\
\hline
\end{tabular}

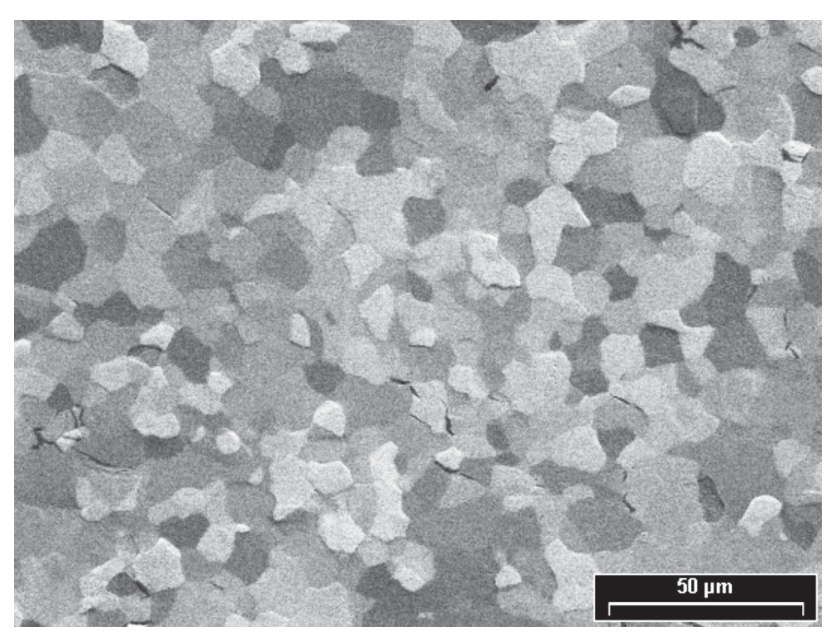

Figure 1. SEM micrograph showing the Zircaloy-4 microstructure. chine, MTS 810. Load (P), crack mouth opening displacement $(\delta)$, and load line displacement $(\mathrm{v})$ were measured using load cell, clip gauge and LVDT transducers. A data acquisition system was used, recording the data in two graphs, one a Load versus crack mouth opening displacement and another with amplified Load vs. amplified crack mouth opening displacement; the latter only during the unloading and reloading cycles in order to measure the compliance.

All specimens were tested at room temperature under displacement control with a displacement speed of $2 \mathrm{~mm} / \mathrm{s}$.

Specimens were tested after precracking by using the single specimen unloading compliance technique, following the ASTM E 1820-99 standard. The data were rotationcorrected using the formulation introduced in ref. (5). The final crack length was marked by fatigue postcracking because the conventional method used in steels, i.e. heat tinting, works by surface oxidation, this making it inappropriate for posterior SEM observation.

J-R curves were obtained in all cases where stable crack growth was present. Values of $\mathrm{J}$ at crack growth initiation, $\mathrm{J}_{\mathrm{IC}}$, for $1 \mathrm{~mm}$ of stable crack growth, $\mathrm{J}_{1 \mathrm{~mm}}$, and the curve slope at this point, $\varphi_{1 \mathrm{~mm}}$, were determined. For those specimens that fractured in brittle mode, the corresponding $\mathrm{J}_{\mathrm{C}}$ values were calculated.

Hydrogen content was measured in all specimens after tests by means of a LECO Hydrogen Determinator equipment, in which a sample is melt inside a EF-400 Electrode Furnace and then gases are filtered into a RH-404 unit to measure their hydrogen content.

Fracture surfaces were observed by means of optic and electronic microscopes.

\section{Results}

Figure 2 shows two typical load-displacement records that were obtained during the tests. The first one is a conventional record, similar to those obtained for homogeneous materials presenting ductile behavior; the second one shows sudden load drops and abrupt changes in the slopes with no complete load recovery.

J-R curves are depicted in Fig. 3. Some specimens initially presented an apparent negative crack growth, Fig. 3a, located in the blunting zone. For these cases the correction proposed in ref. (4) was used.

Due to the fact that $\mathrm{J}_{\mathrm{IC}}$ values obtained showed an important scatter, Fig. 4, the $\mathrm{J}$ and $\varphi$ values for $1 \mathrm{~mm}$ stable crack growth were taken as comparative values, Figure 5 . Table 2 shows the experimental $\mathrm{J}$ and $\varphi$ values obtained for each hydrogen content.

Figure 6 shows a fracture surface observed in a scanning electron microscope, corresponding to a specimen containing $250 \mathrm{ppm}$ of hydrogen. A mixed mode of fracture 
(a)
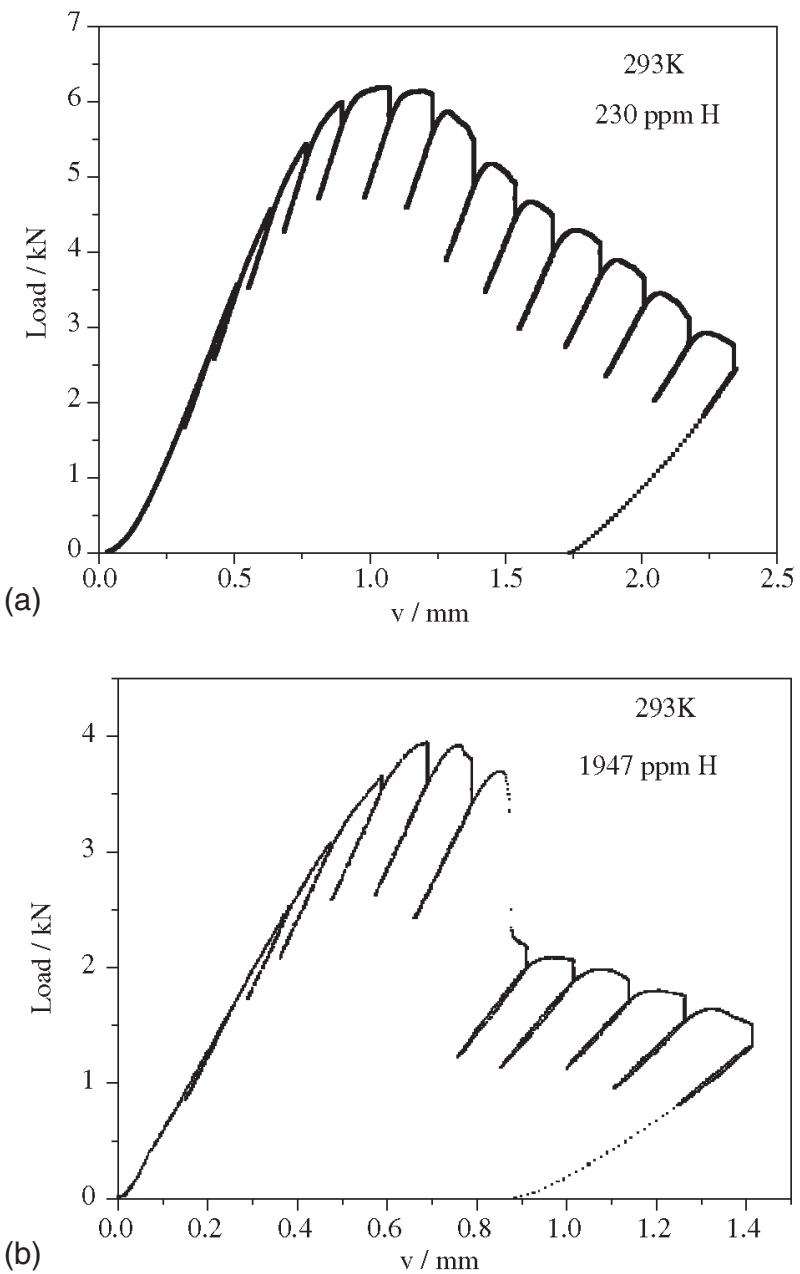

Figure 2. Load - load line displacement records obtained in specimens with different hydrogen contents.

Table 2. $\mathrm{J}_{\mathrm{IC}}, \mathrm{J}_{1 \mathrm{~mm}}, \mathrm{~J}_{\mathrm{C}}$ and $\varphi_{1 \mathrm{~mm}}$ values obtained at different hydrogen contents.

\begin{tabular}{lcccc}
\hline $\begin{array}{l}\mathrm{H} \\
{[\mathrm{ppm}]}\end{array}$ & $\begin{array}{c}\mathrm{J}_{\mathrm{IC}} \\
{\left[\mathrm{kJ} / \mathrm{m}^{2}\right]}\end{array}$ & $\begin{array}{c}\mathrm{J}_{1 \mathrm{~mm}} \\
{\left[\mathrm{~kJ} / \mathrm{m}^{2}\right]}\end{array}$ & $\begin{array}{c}\mathrm{J}_{\mathrm{C}} \\
{\left[\mathrm{kJ} / \mathrm{m}^{2}\right]}\end{array}$ & $\begin{array}{c}\varphi_{1 \mathrm{~mm}} \\
{\left[\mathrm{~kJ} /\left(\mathrm{m}^{2} \mathrm{~mm}\right]\right.}\end{array}$ \\
\hline 290 & Brittle Fracture & - & 12.6 & - \\
119 & 80 & 123 & - & 42.9 \\
43 & 100 & 164 & - & 73.2 \\
114 & 67 & 118 & - & 52.2 \\
153 & 62 & 104 & - & 42.7 \\
273 & 108 & 133 & - & 24.2 \\
400 & 50 & 98 & - & 30.5 \\
150 & 88 & 115 & - & 26.1 \\
378 & 78 & 145 & - & 37.9 \\
1947 & 45 & - & 51.9 & - \\
1960 & 39 & 64 & - & 23.0 \\
10 & 378 & 453 & - & 231.1 \\
\hline
\end{tabular}
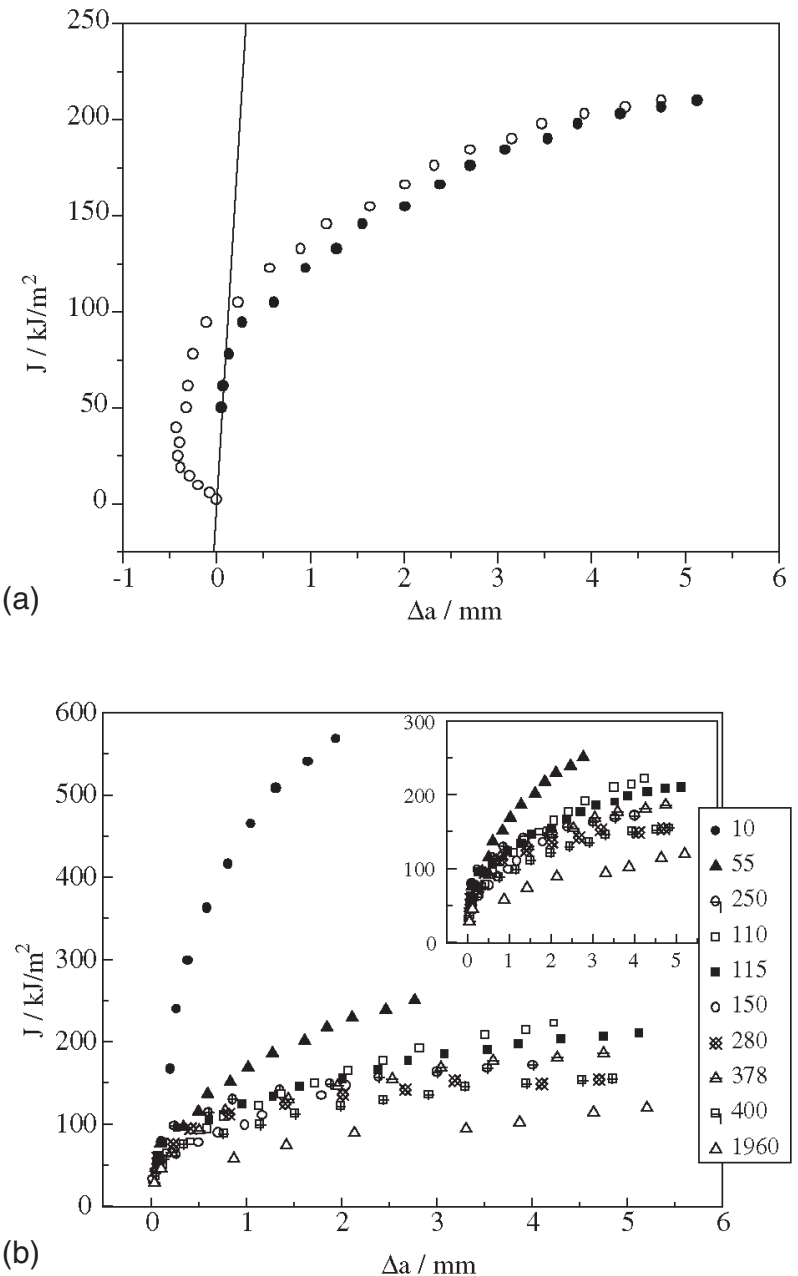

Figure 3. a) Negative crack growth correction on a J-R curve. b) Effects of the hydrogen content on the J-R curves.

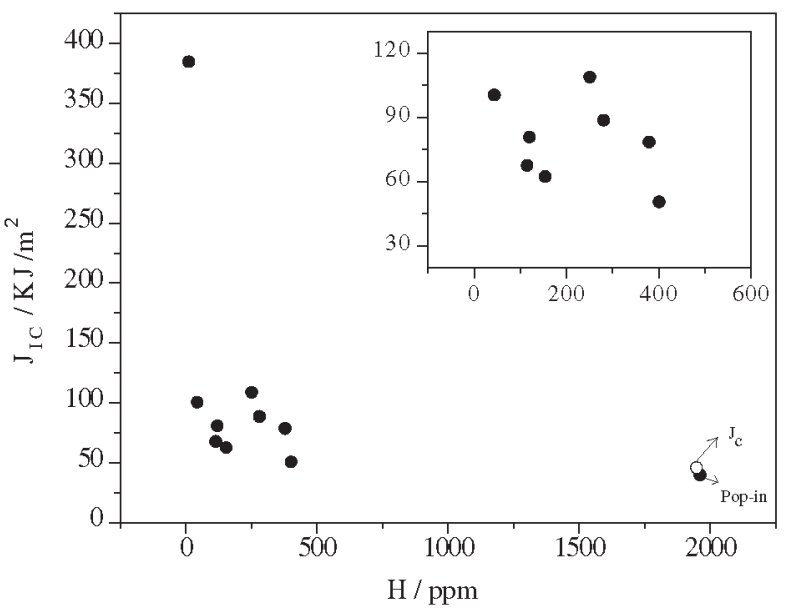

Figure 4. $\mathrm{J}_{\mathrm{IC}}$ as a function of hydrogen content. 

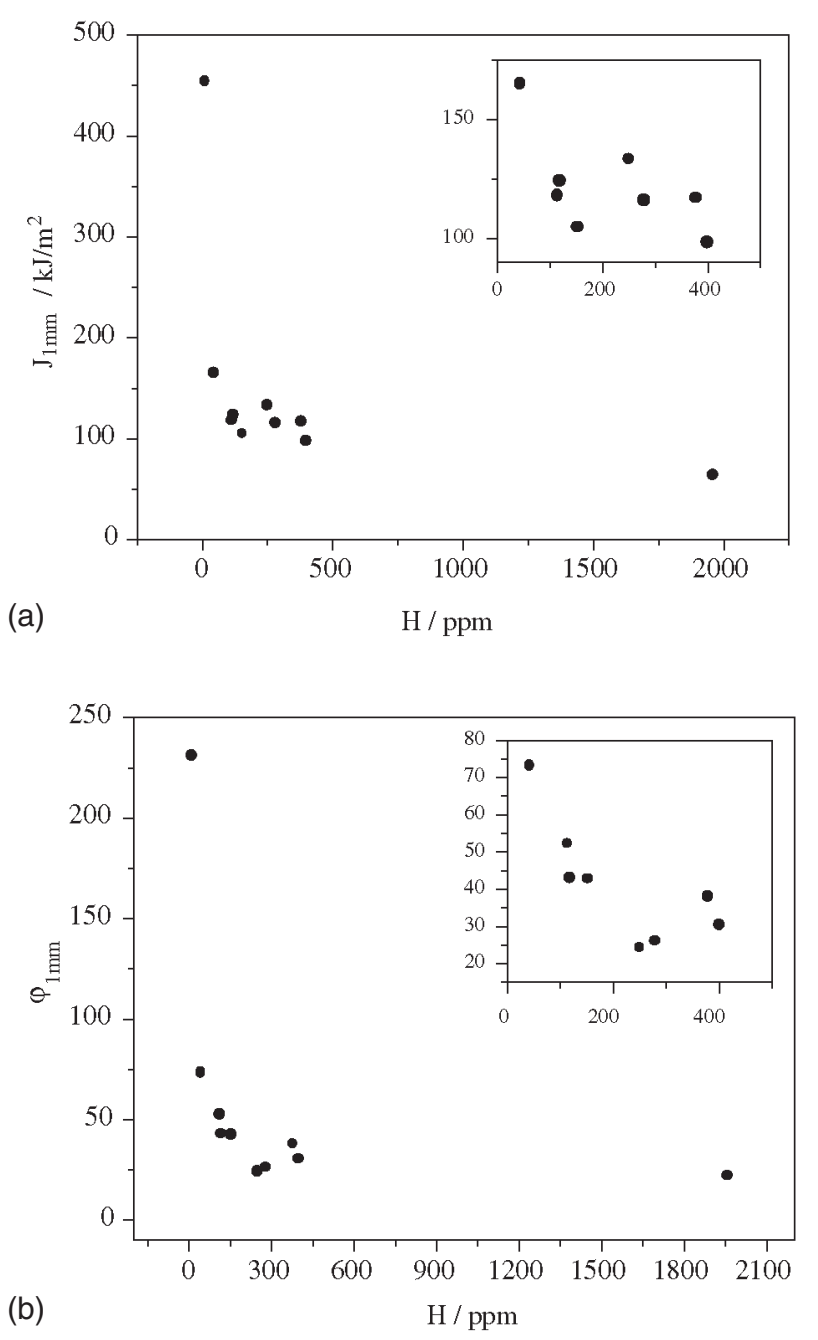

Figure 5. Variation of a) $J_{1 \mathrm{~mm}}$ and b) $\varphi_{1 \mathrm{~mm}}$ with the hydrogen content.

can be observed showing brittle mode zones as well as microvoids coalescence regions. Figure 7 corresponds to a specimen that fractured in brittle mode.

\section{Discussion}

The cathodic charge proved a convenient method for specimen hydrogen precharge. A thin hydride layer precipitated onto its surface. The hydrogen diffused further to the interior when heat treated, giving a homogenized distribution inside the whole specimen. Opposite to the gaseous charge technique, this one did not destroy specimens surface.

Most tests presented ductile behavior, although a few specimens with high hydrogen content failed in brittle mode, or presented instability and posterior crack arrest.
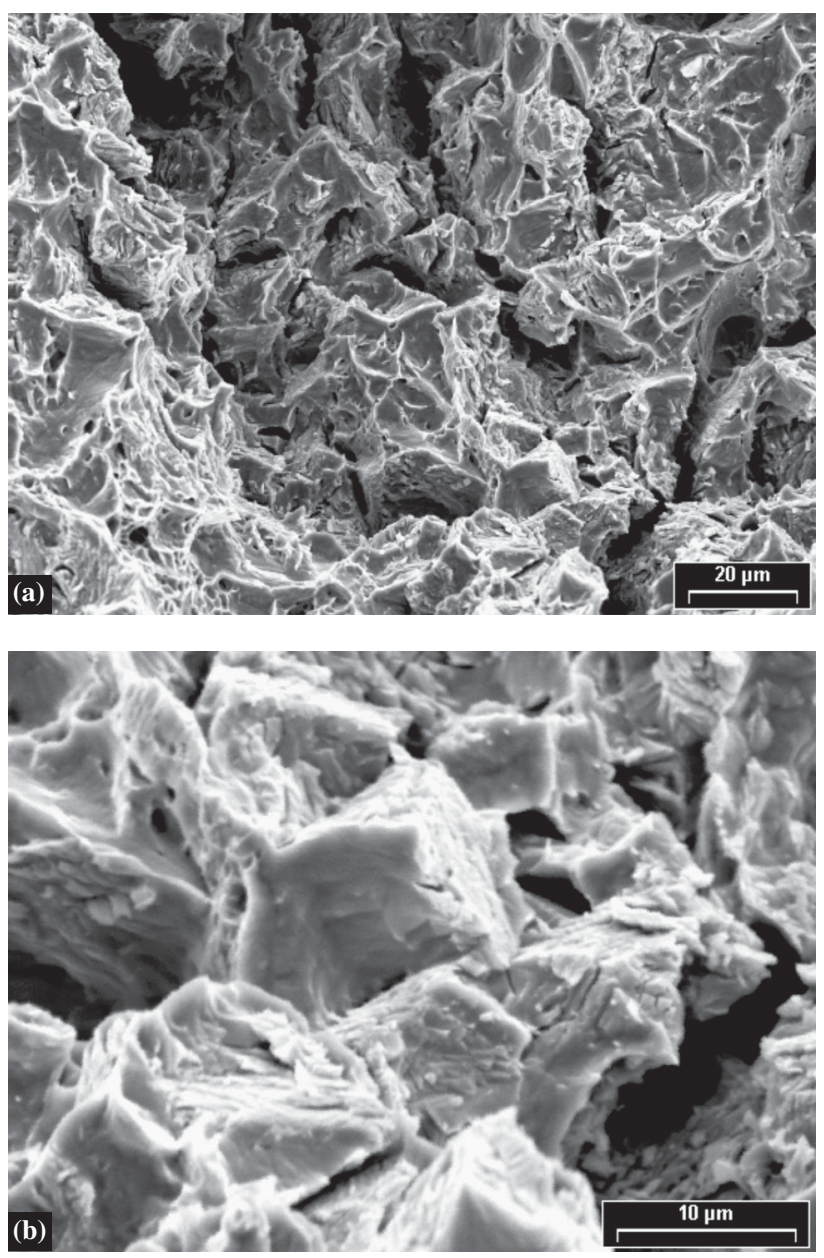

Figure 6. Fracture surface observation by SEM, showing a) mixed mode of fracture, b) a magnified zone of a.

Irregularities observed in the blunting line zone, i.e. apparent negative crack growth, are likely to be attributed to the specimen reduced thickness $(6 \mathrm{~mm})$. Although this effect is well known and has been several times reported ${ }^{2,6}$, the frequency of occurrence during this experience was high, and the correction applied did not give satisfactory results, Fig. 4. This will be the subject of future work.

As it was previously described, results were analyzed for $1 \mathrm{~mm}$ of stable crack growth in order to reduce the influence of the blunting zone. Both parameters, $\mathrm{J}$ and the Rcurve slope, showed a clear tendency to decrease as hydrogen content increased, Fig. 5. The toughness drop was abrupt for low $\mathrm{H}$ contents, below $250 \mathrm{ppm}$, turning gradual for higher concentrations.

Tests for the highest $\mathrm{H}$ contents ( $>1900 \mathrm{ppm}$ ) presented brittle fracture or unstable crack growth with subsequent crack arrest (pop-in). In the first case toughness was char- 

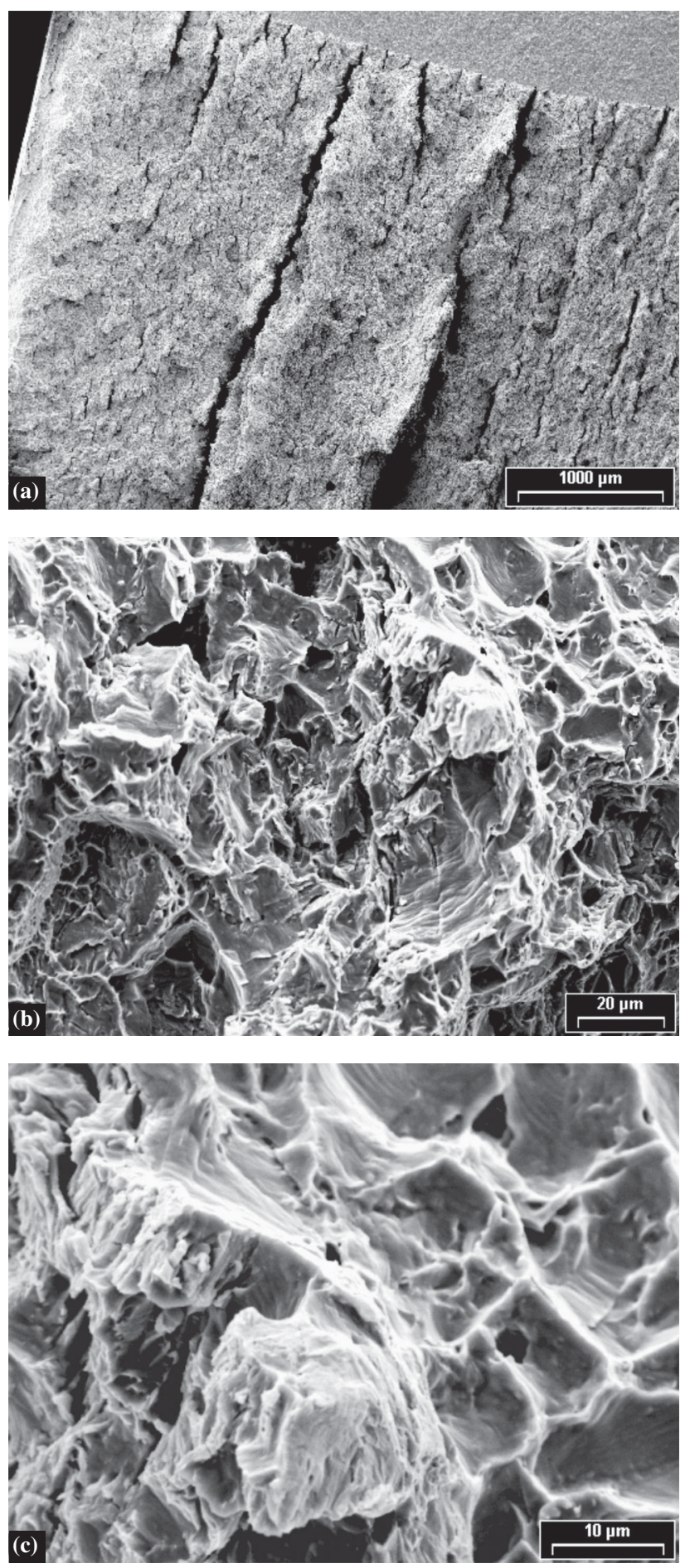

Figure 7. Fracture surface observation by SEM, a) stable crack growth and longitudinal cracks, b) beginning of stable crack growth, c) zoom of b. acterized by $\mathrm{J}$ at instability point, $\mathrm{J}_{\mathrm{C}}$. The fact that pop-in occurred after some stable crack growth allowed initiation values be obtained. Intead, in the case of the specimen that presented brittle fracture, this was close after the initiation, giving a $\mathrm{J}_{\mathrm{C}}$ value higher than $\mathrm{J}_{\mathrm{IC}}$, which does not mean a higher toughness.

Fractographic observations on some surfaces corresponding to specimens that presented neither brittle fracture nor instability during the tests showed areas that looked like cleavage mechanism. The proportion of apparent cleavage zones was higher the higher the hydrogen content.

\section{Conclusions}

Specimens preparation techniques proved satisfactory. Most tests presented ductile behavior, although a few ones with high hydrogen content failed in brittle mode, or presented instability and posterior crack arrest. $\mathrm{J}_{\mathrm{IC}}$ values showed an important scatter in spite of the negative crack growth correction done. When results were analyzed for $\Delta \mathrm{a}=1 \mathrm{~mm}$ values $\left(\mathrm{J}_{1 \mathrm{~mm}}\right.$ and $\left.\varphi_{1 \mathrm{~mm}}\right)$, toughness clearly tended to decrease as hydrogen content increased. Toughness drop was abrupt for low $\mathrm{H}$ contents while gradual for high contents. Fractographic observations presented more cleavage-like area percentage the higher the hydrogen content was. Despite the records presented no signs of brittle fracture, certain specimens showed cleavage-like zones.

\section{References}

1. Davies P.H.; Shewfelt R.S.W. Zirconium in the Nuclear Industry, $11^{\circ}$ International Symposium, ASTM STP 1295, p. 492-517, 1996,

2. Efsing P.; Pettersson K. Zirconium in the Nuclear Industry, $11^{\circ}$ International Symposium, ASTM STP 1295, p. 394-404, 1996,

3. ASTM E 1820-99. Annual Book of ASTM Standards, v. 03.01, p. 972-1005, 1999.

4. Underwood J.H.; Troiano E.J.; Abbott R.T. Fracture Mechanics: $24^{\circ}$ Volume, ASTM STP 1207, Philadelphia, p. 410-421, 1994.

5. Perez Ipiña J.E. Engineering Fracture Mechanics, v. 36, n. 5, p. 797-804, 1990.

6. Dubey J.S.; Wadekar S.L.; Singh R.N.; Sinha T.K. Chakravartty J.K., Journal of Nuclear Materials, v. 264, p. 20-28, 1999. 